\title{
Obesity increases the risk of erosive esophagitis but metabolic unhealthiness alone does not: a large-scale cross-sectional study
}

Myong Ki Baeg ${ }^{1}$, Sun-Hye Ko ${ }^{2^{*}}$ (D), Seung Yeon $\mathrm{Ko}^{3}$, Hee Sun Jung ${ }^{4}$ and Myung-Gyu Choi ${ }^{5}$

\begin{abstract}
Background: Obesity is a known risk factor for erosive esophagitis (EE) and metabolic unhealthiness has been implicated in EE pathogenesis. However, obesity and metabolic unhealthiness are not synonymous and the associations between obesity, metabolic health, and EE are unclear. Therefore, our aim was to investigate the relationship between $\mathrm{EE}$, obesity, and metabolic health.

Methods: We performed a retrospective cross-sectional study of subjects undergoing health screening at a university hospital. Subjects were classified into 4 groups based on metabolic and obesity criteria: metabolically healthy nonobese (MHNO), metabolically healthy obese (MHO), metabolically unhealthy nonobese (MUNO), and metabolically unhealthy obese (MUO). Multivariable analysis was used to identify EE risk factors with MHNO subjects as reference. To determine if there were synergistic interactions between metabolic health and obesity status, the Rothman's synergy index and attributable proportion of risk were also calculated.

Results: We included 10,338 subjects (5448 MHNO, 1605 MHO, 1600 MUNO, 1685 MUO). The prevalence of EE was $6.5 \%$ in $\mathrm{MHNO}, 12.6 \%$ in $\mathrm{MHO}, 9.3 \%$ in $\mathrm{MUNO}$, and $14.3 \%$ in MUO. EE risk was increased significantly by obesity (MHO: OR, 1.589, 95\% Cl, 1.314-1.921, $P<0.001$; MUO: OR, 1.734, 95\% Cl, 1.441-2.085, $P<0.001$ ), but not in MUNO subjects $(\mathrm{OR}, 1.224,95 \% \mathrm{Cl}, 0.991-1.511, P=0.060)$. Male sex, blood leukocyte count, alcohol, and smoking significantly increased EE risk, but $\mathrm{H}$. pylori infection was protective. Replacement of obesity with abdominal obesity gave similar results. The Rothman's synergy index was $0.920(95 \% \mathrm{Cl}, 0.143-5.899)$ and the attributable proportion of risk was -0.051 (95\% Cl, - 1.206-1.105), indicating no interaction between metabolic and obesity status on EE risk.

Conclusions: We demonstrated that obesity increased the risk of $\mathrm{EE}$, regardless of metabolic health status. However, EE risk was not significantly increased in MUNO subjects, suggesting that metabolic unhealthiness may not be involved in EE pathogenesis. As observational cross-sectional studies cannot prove causality, prospective longitudinal studies involving obesity and metabolic treatment should be performed to further investigate the association between obesity, metabolic health, and EE risk.
\end{abstract}

Keywords: Erosive esophagitis, Gastroesophageal reflux disease, Metabolic health status, Obesity, Wildman criteria

\footnotetext{
* Correspondence: sunhyeko@gmail.com

${ }^{2}$ Department of Internal Medicine, Inje University Haeundae Paik Hospital, Inje University College of Medicine, 875 Haeundaero, Haeundae-Gu, Busan 612-896, South Korea

Full list of author information is available at the end of the article
}

(c) The Author(s). 2018 Open Access This article is distributed under the terms of the Creative Commons Attribution 4.0 International License (http://creativecommons.org/licenses/by/4.0/), which permits unrestricted use, distribution, and reproduction in any medium, provided you give appropriate credit to the original author(s) and the source, provide a link to the Creative Commons license, and indicate if changes were made. The Creative Commons Public Domain Dedication waiver (http://creativecommons.org/publicdomain/zero/1.0/) applies to the data made available in this article, unless otherwise stated. 


\section{Background}

Gastroesophageal reflux disease (GERD) is a multifactorial disease that has genetic, physiologic and environmental risk factors [1]. One risk factor that has attracted great interest is obesity [2], of which the epidemic increase has paralleled the global increase in GERD [3]. The potential mechanisms linking obesity with GERD are pathophysiologic changes brought on by increased intra-abdominal pressure and metabolic unhealthiness associated with proinflammatory cytokine production and the insulin/insulin growth factor pathway $[1,4]$. Although obesity has often been regarded as being synonymous with metabolic unhealthiness, not all obese people are metabolically unhealthy and one-third of metabolically unhealthy people are of normal weight $[5,6]$. However, the association between obesity, metabolic health, and GERD has not been investigated adequately.

Endoscopically visible breaks in the gastroesophageal junction are a reliable sign of GERD. This is clinically important because healing of such endoscopically confirmed erosive esophagitis (EE) can be regarded as a surrogate for successful therapy and correlates well with symptomatic relief [7]. EE is associated with potentially serious complications such as Barrett's esophagus (BE) and esophageal adenocarcinoma (EAC) [8, 9], which have also been linked with obesity and metabolic unhealthiness [10-12]. Therefore, the aim of our study was to investigate the relationship between EE, obesity, and metabolic health status.

\section{Methods}

\section{Study population}

We performed a retrospective cross-sectional study of subjects who underwent routine health screening from March 2009 to July 2014 at the Center for Health Promotion of Seoul St. Mary's Hospital (Seochogu, Seoul, South Korea). Subjects underwent health screening voluntarily or as part of annual/biannual employee check-ups. Such check-ups cover about $40-50 \%$ of the Korean population. Those who underwent screening esophagogastroduodenoscopy and for whom fasting serum insulin results were available were included in this study. Those who underwent multiple visits had only the first set of endoscopy included. We excluded subjects who 1) had a history of current or previous malignancies, 2) had a history of upper gastrointestinal surgery, and 3) were missing medical or social records or anthropometric/laboratory findings. This study was approved by the Institutional Review Board of Seoul St. Mary's Hospital, which permitted the study without informed consent requirements because it was a retrospective study using blinded subject identities (KC14RISI0574).

\section{Data collection}

Physical characteristics including weight, height, waist circumference, and blood pressure were measured by trained medical personnel. Blood pressure was measured using an appropriately sized cuff with the subject in a sitting position after at least $10 \mathrm{~min}$ of rest. Waist circumference was measured at the midline between the lowest rib and the iliac crest.

Blood samples were taken after an overnight fast of at least $12 \mathrm{~h}$. White blood cell (WBC) counts were analyzed using a Sysmex-XE2100 automated blood cell analyzer (Sysmex, Kobe, Japan). Fasting plasma glucose (FPG), total cholesterol, triglyceride, high-density lipoprotein (HDL) cholesterol, and low-density lipoprotein cholesterol levels were measured using a Hitachi 7600 automated analyzer (Hitachi Co., Tokyo, Japan). Glycated hemoglobin (HbA1c) was measured using a Tosoh HLC-723 HbG7 analyzer (Tosoh Bioscience Ltd., Redditch, UK). Helicobacter pylor$i$-specific immunoglobulin $\mathrm{G}$ concentration was measured using the Immulite 2000 XPi platform (Siemens Healthcare Diagnostics, Erlangen, Germany).

\section{Esophagogastroduodenoscopy}

Esophagogastroduodenoscopy (Olympus GIF-H260; Olympus Ltd., Tokyo, Japan) was performed in subjects who had fasted overnight by endoscopists who were board-accredited gastroenterologists and certified as experts by the Korean Society of Gastrointestinal Endoscopy. EE was defined according to the Los Angeles Classification [13]. All endoscopy results were reassessed visually by two authors who were blinded to the initial endoscopy records.

\section{Definitions}

Body mass index was calculated as weight divided by height squared $\left(\mathrm{kg} / \mathrm{m}^{2}\right)$. Obesity was defined according to the World Health Organization Criteria for East Asians $\left(>25 \mathrm{~kg} / \mathrm{m}^{2}\right)$ [14]. Abdominal obesity was defined as waist circumference $\geq 90 \mathrm{~cm}$ in men and $\geq 80 \mathrm{~cm}$ in women, which are the modified criteria for the Asian population [15]. Insulin resistance was computed by the homeostasis model assessment of insulin resistance (HOMA-IR) as follows: fasting insulin $(\mathrm{pmol} / \mathrm{L}) \times$ fasting glucose $(\mathrm{mmol} / \mathrm{L}) / 22.5$ [16]. Metabolic health status was determined by the modified Wildman criteria, which were as follows: (1) systolic blood pressure $\geq 130 \mathrm{mmHg}$ or diastolic blood pressure $\geq 85 \mathrm{mmHg}$ or use of antihypertensive medication, (2) triglyceride levels $\geq$ $1.7 \mathrm{mmol} / \mathrm{L}$ or use of lipid-lowering drugs, (3) FPG $\geq$ $5.5 \mathrm{mmol} / \mathrm{L}$ or use of antidiabetes therapy, (4) HDL cholesterol levels $<1.0 \mathrm{mmol} / \mathrm{L}$ in men and $<1.3 \mathrm{mmol} /$ $\mathrm{L}$ in women, and (5) HOMA-IR $>90$ th percentile in our population $(\geq 3.17)[6,17,18]$. Subjects were defined as metabolically healthy if they met $\leq 1$ of the modified 
Wildman criteria and metabolically unhealthy if they met $\geq 2$ of the criteria. Based on the modified Wildman and obesity criteria, the subjects were classified as (1) metabolically healthy nonobese (MHNO), (2) metabolically healthy obese (MHO), (3) metabolically unhealthy nonobese (MUNO), and (4) metabolically unhealthy obese (MUO).

\section{Statistical analysis}

Clinical characteristics and parameters were expressed as mean \pm standard deviation or numbers (percentage). Categorical variables were analyzed by Pearson's chi-square test, and continuous variables by analysis of variance. $P$ values $<0.05$ were considered significant. Multivariable regression analysis was performed to identify risk factors for EE. Odds ratios (ORs) and 95\% confidence intervals (CIs) for EE were calculated for the MHO, MUNO, and MUO groups using the MHNO group as the reference category. A separate analysis was performed, replacing obesity with abdominal obesity to investigate its effects. In addition, we analyzed the interaction between metabolic health and obesity status by calculating the Rothman's synergy index and the attributable proportion of risk [19, 20]. If metabolic health and obesity had an interaction to increase the risk of $\mathrm{EE}$, the synergy index would be greater than 1.0, whereas if there were no additive effects, the value would be below 1 . The attributable proportion of risk gives an estimate of the proportion of EE cases that are attributable to any interaction between metabolic health and obesity status beyond each factor alone. If there were any positive interaction, the attributable proportion of risk would be greater than 0 [19].

\section{Results}

During routine health screening in the study period, 14,368 Koreans underwent screening esophagogastroduodenoscopy and fasting insulin measurement. Of these, 4030 were excluded for the following reasons: (1) 150 because of repeat testing, (2) 89 with malignancies, (3) three with prior upper gastrointestinal surgery, and (4) 3788 with missing social or medical records or anthropometric/laboratory data. Of the 10,338 subjects included in the study, there were 5448 in the MHNO group, 1605 in the MHO group, 1600 in the MUNO group, and 1685 in the MUO group (Fig. 1).

The prevalence of EE was $6.5 \%$ in the MHNO group, $12.6 \%$ in the MHO group, $9.3 \%$ in the MUNO group, and $14.3 \%$ in the MUO group. There was a significantly higher proportion of males in the obese groups. Indices related to glucose metabolism such as FPG, HbA1c, insulin, and HOMA-IR were lowest in the MHNO group and successively increased in the MHO, MUNO, and MUO groups. The percentage of subjects who drank coffee or alcohol was significantly higher in the obese groups. Other characteristics of the four groups are listed in Table 1.

Characteristics of the subjects based on EE status are shown in Table 2. Subjects with EE were significantly more likely to be male and obese, and included significantly more subjects who drank coffee or alcohol and had a smoking history. Those with EE were significantly less likely to be seropositive for $H$. pylori.

Univariable analysis of EE risk factors found that male sex, higher WBC count, higher glucose metabolism indices, drinking coffee or alcohol, or smoking significantly increasedEE risk. Protective factors for EE were higher HDL cholesterol levels and H. pylori seropositivity (Table 3).

Multivariable analysis found that compared with the reference MHNO group, EE risk was significantly higher in the obese groups (MHO: OR, 1.589, 95\% CI, 1.314-1.921, $P<0.001$; MUO: OR, 1.734, 95\% CI, 1.441-2.085, $P<$ 0.001 ), but not in the MUNO group (OR, 1.224, 95\% CI,

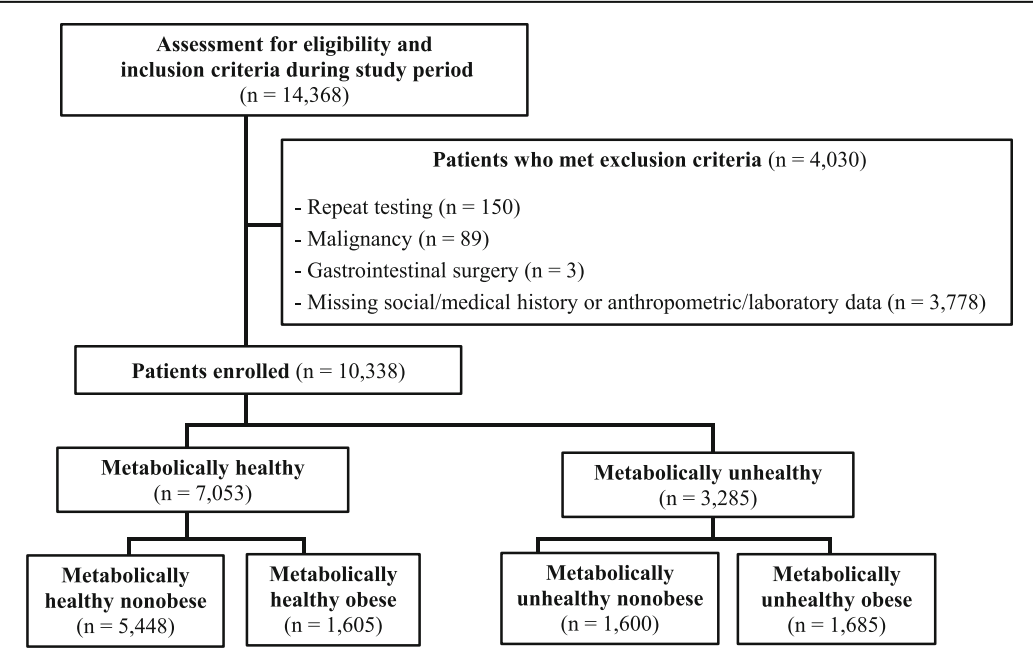

Fig. 1 Flow chart of the study design 
Table 1 Characteristics of subjects by metabolic obesity status

\begin{tabular}{|c|c|c|c|c|c|}
\hline & $\begin{array}{l}\text { MHNO } \\
(n=5448)\end{array}$ & $\begin{array}{l}\text { MHO } \\
(n=1605)\end{array}$ & $\begin{array}{l}\text { MUNO } \\
(n=1600)\end{array}$ & $\begin{array}{l}\text { MUO } \\
(n=1685)\end{array}$ & $P$ \\
\hline Age (years) & $49.5 \pm 11.4$ & $51.6 \pm 11.1$ & $56.5 \pm 10.3$ & $53.9 \pm 11.2$ & $<0.001$ \\
\hline Male $(n, \%)$ & $2339(42.9 \%)$ & $1074(66.9 \%)$ & $921(57.6 \%)$ & $1204(71.5 \%)$ & $<0.001$ \\
\hline Diabetes (n, \%) & $153(2.8 \%)$ & $50(3.1 \%)$ & $418(26.1 \%)$ & $467(27.7 \%)$ & $<0.001$ \\
\hline Hypertension (n, \%) & $582(10.7 \%)$ & $328(20.4 \%)$ & $616(38.5 \%)$ & $682(40.5 \%)$ & $<0.001$ \\
\hline BMI $\left(\mathrm{kg} / \mathrm{m}^{2}\right)$ & $21.7 \pm 2.0$ & $26.8 \pm 1.7$ & $22.9 \pm 1.6$ & $27.6 \pm 2.3$ & $<0.001$ \\
\hline Abdominal obesity (n, \%) & $1454(26.7 \%)$ & $1127(70.2 \%)$ & $574(35.9 \%)$ & $1320(78.3 \%)$ & $<0.001$ \\
\hline Coffee $(n, \%)$ & $3664(67.3 \%)$ & $1156(72.0 \%)$ & 1025 (64.1\%) & $1240(73.6 \%)$ & $<0.001$ \\
\hline Alcohol (n, \%) & $2337(42.9 \%)$ & $932(58.1 \%)$ & 735 (45.9\%) & $949(56.3 \%)$ & $<0.001$ \\
\hline Smoking (n, \%) & $1883(34.6 \%)$ & 705 (43.9\%) & 715 (44.7\%) & $886(52.6 \%)$ & $<0.001$ \\
\hline H.pylori seropositive (n, \%) & $2757(50.6 \%)$ & 839 (52.3\%) & $863(53.9 \%)$ & $922(54.7 \%)$ & 0.008 \\
\hline WBC count $\left(\times 10^{9} / \mathrm{L}\right)$ & $5.4 \pm 1.7$ & $5.7 \pm 1.6$ & $6.0 \pm 1.8$ & $6.3 \pm 1.7$ & $<0.001$ \\
\hline FPG $(\mathrm{mmol} / \mathrm{L})$ & $4.9 \pm 0.8$ & $5.1 \pm 0.7$ & $6.1 \pm 1.8$ & $6.2 \pm 1.6$ & $<0.001$ \\
\hline $\mathrm{HbA1c}(\%)$ & $5.4 \pm 0.5$ & $5.5 \pm 0.5$ & $6.0 \pm 1.1$ & $6.1 \pm 1.0$ & $<0.001$ \\
\hline Insulin (pmol/L) & $34.7 \pm 21.5$ & $50.0 \pm 27.1$ & $54.9 \pm 38.9$ & $80.6 \pm 61.8$ & $<0.001$ \\
\hline HOMA-IR & $1.1 \pm 0.7$ & $1.6 \pm 0.9$ & $2.2 \pm 2.0$ & $3.2 \pm 2.5$ & $<0.001$ \\
\hline Total cholesterol (mmol/L) & $5.1 \pm 0.9$ & $5.2 \pm 0.9$ & $5.2 \pm 1.0$ & $5.2 \pm 1.1$ & $<0.001$ \\
\hline Triglyceride (mmol/L) & $0.9 \pm 0.5$ & $1.1 \pm 0.6$ & $1.8 \pm 1.1$ & $2.0 \pm 1.3$ & $<0.001$ \\
\hline HDL-cholesterol (mmol/L) & $1.5 \pm 0.3$ & $1.3 \pm 0.3$ & $1.2 \pm 0.3$ & $1.1 \pm 0.3$ & $<0.001$ \\
\hline LDL-cholesterol (mmol/L) & $3.1 \pm 0.8$ & $3.3 \pm 0.8$ & $3.1 \pm 0.9$ & $3.2 \pm 0.9$ & $<0.001$ \\
\hline $\mathrm{EE}(\mathrm{n}, \%)$ & $356(6.5 \%)$ & $202(12.6 \%)$ & 149 (9.3\%) & $241(14.3 \%)$ & $<0.001$ \\
\hline EE grade $(n, \%)$ & & & & & $<0.001$ \\
\hline A & $310(5.7 \%)$ & $172(10.7 \%)$ & $127(7.9 \%)$ & $186(11.0 \%)$ & \\
\hline B & $37(0.1 \%)$ & $27(1.7 \%)$ & $19(1.2 \%)$ & $45(2.7 \%)$ & \\
\hline Cor D & $9(0.2 \%)$ & $3(0.2 \%)$ & $3(0.2 \%)$ & $10(0.6 \%)$ & \\
\hline
\end{tabular}

Data are presented as either mean \pm standard deviation or as number (\%)

$B M I$ body mass index, EE erosive esophagitis, FPG fasting plasma glucose, HbA1c glycated hemoglobin, $H D L$ high density lipoprotein, $H O M A-I R$ homeostasis model assessment of insulin resistance, $M H N O$ metabolic healthy nonobese, $M H O$ metabolic healthy obese, $M U N O$ metabolic unhealthy nonobese, $M U O$ metabolic unhealthy obese, $L D L$ low density lipoprotein, $T C$ total cholesterol, WBC white blood cell

0.991-1.511, $P=0.060)$. Other predictive factors for $\mathrm{EE}$ were male sex, higher WBC counts, alcohol, and smoking history while $H$. pylori seropositivity remained protective (Table 4). When obesity was replaced in the analysis with abdominal obesity, the risk factors for EE remained similar. EE risk was significantly higher in the groups with abdominal obesity but not in the metabolically healthy abdominally nonobese group (Table 4). Analyzing obesity and metabolic health separately by multivariable analysis gave similar results, with obesity being a significant risk factor for $\mathrm{EE}$ (OR, 1.521, 95\% CI, 1.314-1.761, $P<0.001$ ), but metabolic health was not significant (OR, 1.154, 95\% CI, 0.992-1.342, $P=0.064)$.

We calculated the Rothman's synergy index and attributable proportion of risk to identify any interaction between metabolic health and obesity on EE. The Rothman's synergy index and the attributable proportion of risk was $0.920(<1,95 \% \mathrm{CI}, 0.143-5.899)$ and -0.051 (<0, 95\% CI, -1.206-1.105), respectively, which suggest that there were no synergistic effects or increased risks from the interaction between them.

\section{Discussion}

This study demonstrated that obesity increases the risk of EE, regardless of metabolic health status. Nonobese metabolically unhealthy subjects did not have a significant increase in EE risk while there was a significant increase in those who were obese. These findings were consistent when abdominal obesity replaced obesity in the analysis. Our study shows that obesity or abdominal obesity plays a significant role in EE risk, whereas metabolic health may not.

Our study reinforced the classic view that obesity or abdominal obesity increases EE risk [1, 21]. This is most likely because of the increased intraabdominal pressure, increased transient lower esophageal sphincter relaxation and anatomic disruption of the esophagogastric junction brought on by obesity or abdominal obesity $[1,21]$. 
Table 2 Characteristics of subjects with or without erosive esophagitis

\begin{tabular}{|c|c|c|c|}
\hline & $\mathrm{EE}(-)(n=9390)$ & $\mathrm{EE}(+)(n=948)$ & $P$ \\
\hline Age (years) & $51.7 \pm 11.4$ & $51.2 \pm 11.6$ & 0.193 \\
\hline Male (n, \%) & $4780(50.9 \%)$ & $758(80.0 \%)$ & $<0.001$ \\
\hline Diabetes (n, \%) & $963(10.3 \%)$ & $125(13.2 \%)$ & 0.005 \\
\hline Hypertension (n, \%) & 1960 (20.9\%) & $248(26.2 \%)$ & $<0.001$ \\
\hline Obesity (n, \%) & 2847 (30.3\%) & $443(46.7 \%)$ & $<0.001$ \\
\hline Abdominal obesity (n, \%) & $4040(43.0 \%)$ & $432(45.6 \%)$ & 0.119 \\
\hline Metabolic unhealthiness ( $\mathrm{n}, \%)$ & 2895 (30.8\%) & $390(41.1 \%)$ & $<0.001$ \\
\hline Metabolic obesity status (n, \%) & & & $<0.001$ \\
\hline Metabolic healthy nonobese & $5092(54.2 \%)$ & $356(37.6 \%)$ & \\
\hline Metabolic healthy obese & $1403(14.9 \%)$ & $202(21.3 \%)$ & \\
\hline Metabolic unhealthy nonobese & $1451(15.5 \%)$ & 149 (15.7\%) & \\
\hline Metabolic unhealthy obese & $1444(15.4 \%)$ & $241(25.4 \%)$ & \\
\hline Metabolic abdominal obesity status (n, \%) & & & $<0.001$ \\
\hline Metabolic healthy abdominal nonobese & $4122(43.9 \%)$ & $351(37.0 \%)$ & \\
\hline Metabolic healthy abdominal obese & $2373(25.3 \%)$ & $207(21.8 \%)$ & \\
\hline Metabolic unhealthy abdominal nonobese & $1228(13.1 \%)$ & $165(17.4 \%)$ & \\
\hline Metabolic unhealthy abdominal obese & $1667(17.8 \%)$ & $225(23.7 \%)$ & \\
\hline Smoking (n, \%) & $3634(38.7 \%)$ & $555(58.5 \%)$ & $<0.001$ \\
\hline Alcohol (n, \%) & $4321(46.0 \%)$ & $632(66.7 \%)$ & $<0.001$ \\
\hline Coffee $(n, \%)$ & $6386(68.0 \%)$ & $699(73.7 \%)$ & $<0.001$ \\
\hline \multicolumn{4}{|l|}{ Laboratory findings } \\
\hline Helicobacter pylori seropositive $(n, \%)$ & $5080(54.1 \%)$ & $301(31.8 \%)$ & $<0.001$ \\
\hline White blood cell count $\left(\times 10^{9} / \mathrm{L}\right)$ & $5.7 \pm 1.7$ & $6.1 \pm 1.8$ & $<0.001$ \\
\hline Fasting plasma glucose (mmol/L) & $5.3 \pm 1.3$ & $5.5 \pm 1.6$ & $<0.001$ \\
\hline Glycated hemoglobin (\%) & $5.6 \pm 0.7$ & $5.8 \pm 0.9$ & $<0.001$ \\
\hline Insulin (pmol/L) & $6.7 \pm 5.5$ & $7.8 \pm 5.7$ & $<0.001$ \\
\hline HOMA-IR & $1.65 \pm 1.57$ & $2.01 \pm 2.05$ & $<0.001$ \\
\hline Total cholesterol (mmol/L) & $5.2 \pm 1.0$ & $5.2 \pm 0.9$ & 0.719 \\
\hline Triglyceride (mmol/L) & $1.2 \pm 0.9$ & $1.5 \pm 1.1$ & $<0.001$ \\
\hline High density lipoprotein cholesterol (mmol/L) & $1.4 \pm 0.3$ & $1.3 \pm 0.3$ & $<0.001$ \\
\hline Low density lipoprotein cholesterol (mmol/L) & $3.2 \pm 0.8$ & $3.2 \pm 0.8$ & 0.628 \\
\hline
\end{tabular}

Data are presented as either mean \pm standard deviation or as number (\%)

EE erosive esophagitis, HOMA-IR homeostasis model assessment of insulin resistance

Recently, a new perspective has suggested that GERD is also mediated by a metabolic pathway [4]. This is supported by several studies that have reported a positive association between insulin resistance and GERD [22-24]. However, these studies were limited by their small number of subjects, that they included only obese subjects without a nonobese control group or had potential multicollinearity issues [22-24]. Most importantly, obesity and metabolic unhealthiness were not analyzed independently, which may have confounded the outcome. In our study, EE risk was dependent on obesity but not on metabolic status. This suggests that metabolic unhealthiness by itself may not be a sufficient risk factor for $\mathrm{EE}$, but is subordinate to obesity.
Interestingly, our study also found that increased WBC counts may increase EE risk. The WBC count is a biomarker of systemic inflammation and has been associated with increased overall, cancer-related, and vascular disease-related mortality [25]. Though metabolic unhealthiness was not associated with the risk of $\mathrm{EE}$, the significant increase in WBC count in subjects with $\mathrm{EE}$ subjects suggests that inflammatory processes may contribute to EE. This is supported by a recent study that reported that subjects with erosive esophagitis had significantly higher standardized ${ }^{18} \mathrm{~F}$-fluorodeoxyglucose uptake values at the esophagogastric junction [26]. It is also supported by studies that have reported that levels of proinflammatory 
Table 3 Univariable risk factors of erosive esophagitis

\begin{tabular}{|c|c|c|c|}
\hline & Odds ratio & 95\% Confidence interval & $P$ \\
\hline Age & 0.996 & $0.990-1.002$ & 0.193 \\
\hline Male & 3.848 & $3.265-4.534$ & $<0.001$ \\
\hline Diabetes & 1.329 & $1.089-1.623$ & 0.005 \\
\hline Hypertension & 1.343 & $1.152-1.566$ & $<0.001$ \\
\hline Obesity & 2.024 & $1.768-2.316$ & $<0.001$ \\
\hline Coffee & 1.321 & $1.135-1.536$ & $<0.001$ \\
\hline Alcohol & 2.346 & $2.038-2.701$ & $<0.001$ \\
\hline Smoking & 2.237 & $1.953-2.562$ & $<0.001$ \\
\hline Helicobacter pylori seropositivity & 0.395 & $0.342-0.455$ & $<0.001$ \\
\hline White blood cell count & 1.145 & $1.105-1.185$ & $<0.001$ \\
\hline Fasting plasma glucose & 1.006 & $1.004-1.008$ & $<0.001$ \\
\hline Glycated hemoglobin & 1.206 & $1.121-1.298$ & $<0.001$ \\
\hline Insulin & 1.027 & $1.017-1.037$ & $<0.001$ \\
\hline HOMA-IR & 1.1 & $1.065-1.137$ & $<0.001$ \\
\hline Total cholesterol & 1 & $0.999-1.002$ & 0.719 \\
\hline Triglyceride & 1.003 & $1.003-1.004$ & $<0.001$ \\
\hline High density lipoprotein cholesterol & 0.979 & $0.974-0.985$ & $<0.001$ \\
\hline Low density lipoprotein cholesterol & 1.001 & $0.998-1.003$ & 0.628 \\
\hline \multicolumn{4}{|l|}{ Metabolic Obesity status } \\
\hline Metabolic healthy nonobese & 1 & & \\
\hline Metabolic healthy obese & 2.059 & $1.716-2.472$ & $<0.001$ \\
\hline Metabolic unhealthy nonobese & 1.469 & $1.203-1.794$ & $<0.001$ \\
\hline Metabolic unhealthy obese & 2.387 & $2.007-2.840$ & $<0.001$ \\
\hline \multicolumn{4}{|l|}{ Metabolic abdominal obesity status } \\
\hline Metabolic healthy abdominal nonobese & 1 & & \\
\hline Metabolic healthy abdominal obese & 1.024 & $0.856-1.225$ & 0.792 \\
\hline Metabolic unhealthy abdominal nonobese & 1.578 & $1.298-1.919$ & $<0.001$ \\
\hline Metabolic unhealthy abdominal obese & 1.585 & $1.328-1.892$ & 0.001 \\
\hline
\end{tabular}

cytokines such as interleukins 1, 6, and 8 were increased in subjects with GERD [27]. However, as both EE and non-EE subjects had WBC counts within the normal range and MUNO subjects had higher WBC counts than MHO subjects, the association between higher WBC counts and increased EE risk cannot be asserted confidently. Studies involving EE and the inflammatory pathway should be performed to further investigate this association.

Our study is limited by its retrospective cross-sectional design, which allows only inferences to be made regarding obesity/metabolic health status and risk of EE. Another limitation is the lack of data regarding inflammatory factors such as interleukin $1,6,8$, and tumor necrosis factor alpha, which may have shed more light on the association between inflammation and EE. A third limitation is that we only included subjects for whom both insulin and endoscopy results were available, which may have resulted in a selection bias. However, because our study included over 10,000 subjects, we believe that the risk of selection bias is low. Finally, we could not investigate the association between $\mathrm{BE}$ or $\mathrm{EAC}$ and obesity/metabolic health because the prevalence of $\mathrm{BE}$ and EAC is very low in Koreans [28, 29].

The main strength of our study is that this is the first study investigating the risk of EE according to a standardized obesity/metabolic health profile to divide the subjects into four distinct obesity/metabolic groups. This enabled us to distinguish the effects of obesity and metabolic health, which contrasts with previous studies whose findings may have been related to underlying obesity rather than to metabolic unhealthiness [22, 24]. Another strength is the large number of subjects included in our study, with at least 1600 subjects in each subgroup. Though this study was of a retrospective cross-sectional design, we believe that the inclusion of a 
Table 4 Multivariable risk factors of erosive esophagitis according to metabolic obesity status or metabolic abdominal obesity status

\begin{tabular}{|c|c|c|c|c|c|c|}
\hline & Odds ratio & $95 \% \mathrm{Cl}$ & $P$ & Odds ratio & $95 \% \mathrm{Cl}$ & $P$ \\
\hline Age & 1.002 & $0.996-1.008$ & 0.540 & 1 & $0.994-1.006$ & 0.982 \\
\hline Male & 2.691 & $2.196-3.297$ & $<0.001$ & 3.358 & $2.727-4.136$ & $<0.001$ \\
\hline Coffee & 1.075 & $0.918-1.258$ & 0.369 & 1.087 & $0.929-1.273$ & 0.298 \\
\hline Alcohol & 1.338 & $1.138-1.574$ & $<0.001$ & 1.346 & $1.145-1.583$ & $<0.001$ \\
\hline Smoking & 1.181 & $1.007-1.385$ & 0.041 & 1.171 & $0.999-1.373$ & 0.052 \\
\hline Helicobacter pylori seropositivity & 0.362 & $0.313-0.419$ & $<0.001$ & 0.364 & $0.315-0.422$ & $<0.001$ \\
\hline White blood cell count & 1.071 & $1.029-1.114$ & 0.001 & 1.068 & $1.027-1.111$ & 0.001 \\
\hline \multicolumn{7}{|l|}{ Metabolic Obesity Status } \\
\hline Metabolic healthy nonobese & 1 & & & & & \\
\hline Metabolic healthy obese & 1.589 & $1.314-1.921$ & $<0.001$ & & & \\
\hline Metabolic unhealthy nonobese & 1.224 & $0.991-1.511$ & 0.06 & & & \\
\hline Metabolic unhealthy obese & 1.734 & $1.441-2.085$ & $<0.001$ & & & \\
\hline \multicolumn{7}{|l|}{ Metabolic Abdominal Obesity Status } \\
\hline Metabolic healthy abdominal nonobese & & & & 1 & & \\
\hline Metabolic healthy abdominal obese & & & & 1.585 & $1.308-1.920$ & $<0.001$ \\
\hline Metabolic unhealthy abdominal nonobese & & & & 1.186 & $0.966-1.455$ & 0.103 \\
\hline Metabolic unhealthy abdominal obese & & & & 1.807 & $1.496-2.182$ & $<0.001$ \\
\hline
\end{tabular}

sufficiently large number of subjects lends credibility to our study results. Lastly, we calculated the Rothman's synergy index and attributable proportion of risk to determine if there was any interaction between metabolic health and obesity status. This analysis verified our findings in that there were no significant interactions between metabolic health and obesity status, which also suggests that the risk of EE conferred by obesity was independent of metabolic health status.

\section{Conclusion}

Our study found that obesity/abdominal obesity was a risk factor for EE, regardless of metabolic health status. Though EE risk was significantly increased in the MUO group compared with the reference MHNO group, it was not in the MUNO group, which suggests that metabolic health plays a marginal role in EE pathogenesis. Prospective longitudinal studies including body composition and metabolic health analysis as in addition to those involving obesity and metabolic treatment should be performed to further investigate the association between obesity, metabolic health, and EE risk.

\footnotetext{
Abbreviations

BE: Barrett's esophagus; Cl: Confidence interval; EAC: Esophageal adenocarcinoma; EE: Erosive esophagitis; FPG: Fasting plasma glucose; GERD: Gastroesophageal reflux disease; HbA1c: Glycated hemoglobin; HOMA-IR: Homeostasis model assessment of insulin resistance; MHNO: Metabolically healthy nonobese; MHO: Metabolically healthy obese; MUNO: Metabolically unhealthy nonobese; MUO: Metabolically unhealthy obese; OR: Odds ratio; WBC: White blood cell
}

\section{Funding}

This work was supported by the research fund of International St. Mary's Hospital, Catholic Kwandong University.

\section{Availability of data and materials}

Data are available in case of reasonable request from the corresponding author.

\section{Authors' contributions}

S-HK, MKB, and SYK designed the study. MKB, SYK and HSJ collected the data. HSJ and M-GC analyzed the data. S-HK and MKB wrote the manuscript. S-HK and M-GC edited the manuscript. We also state that all authors have read and approved the manuscript.

\section{Ethics approval and consent to participate}

This study was approved by the Institutional Review Board of Seoul St. Mary's Hospital (KC14RISI0574). Informed consent was not acquired as this was a retrospective study using blinded subject identities.

\section{Competing interests}

The authors declare that they have no competing interests.

\section{Publisher's Note}

Springer Nature remains neutral with regard to jurisdictional claims in published maps and institutional affiliations.

\footnotetext{
Author details

'Department of Internal Medicine, International St. Mary's Hospital, College of Medicine, Catholic Kwandong University, Incheon 22711, South Korea. ${ }^{2}$ Department of Internal Medicine, Inje University Haeundae Paik Hospital, Inje University College of Medicine, 875 Haeundaero, Haeundae-Gu, Busan 612-896, South Korea. ${ }^{3}$ Department of Surgery, Sacred Heart Hospital, Hallym University, Gyeonggi-do, Anyang-si 14068, South Korea. ${ }^{4}$ Department of Health Promotion, Seoul St. Mary's Hospital, College of Medicine, The Catholic University of Korea, Seoul 06591, South Korea. ${ }^{5}$ Department of Internal Medicine, Seoul St. Mary's Hospital, College of Medicine, The Catholic University of Korea, Seoul 06591, South Korea.
} 
Received: 31 January 2018 Accepted: 31 May 2018

Published online: 08 June 2018

\section{References}

1. Boeckxstaens G, El-Serag HB, Smout AJ, Kahrilas PJ. Symptomatic reflux disease: the present, the past and the future. Gut. 2014;63(7):1185-93.

2. Hampel H, Abraham NS, El-Serag HB. Meta-analysis: obesity and the risk for gastroesophageal reflux disease and its complications. Ann Intern Med. 2005:143(3):199-211.

3. Ng M, Fleming T, Robinson M, Thomson B, Graetz N, Margono C, Mullany EC, Biryukov S, Abbafati C, Abera SF, et al. Global, regional, and national prevalence of overweight and obesity in children and adults during 19802013: a systematic analysis for the global burden of disease study 2013. Lancet. 2014;384(9945):766-81.

4. Tilg H, Moschen AR. Visceral adipose tissue attacks beyond the liver: esophagogastric junction as a new target. Gastroenterology. 2010;139(6):1823-6.

5. Stefan N, Kantartzis K, Machann J, Schick F, Thamer C, Rittig K, Balletshofer B, Machicao F, Fritsche A, Haring HU. Identification and characterization of metabolically benign obesity in humans. Arch Intern Med. 2008;168(15):1609-16.

6. Wildman RP, Muntner P, Reynolds K, McGinn AP, Rajpathak S, Wylie-Rosett J, Sowers MR. The obese without cardiometabolic risk factor clustering and the normal weight with cardiometabolic risk factor clustering: prevalence and correlates of 2 phenotypes among the US population (NHANES 19992004). Arch Intern Med. 2008:168(15):1617-24.

7. Vakil N, van Zanten SV, Kahrilas P, Dent J, Jones R. The Montreal definition and classification of gastroesophageal reflux disease: a global evidencebased consensus. Am J Gastroenterol. 2006;101(8):1900-20. quiz 1943

8. Shaheen N, Ransohoff DF. Gastroesophageal reflux, Barrett esophagus, and esophageal cancer: scientific review. JAMA. 2002;287(15):1972-81.

9. Lagergren J, Bergstrom R, Lindgren A, Nyren O. Symptomatic gastroesophageal reflux as a risk factor for esophageal adenocarcinoma. N Engl J Med. 1999;340(11):825-31.

10. Duggan C, Onstad L, Hardikar S, Blount PL, Reid BJ, Vaughan TL. Association between markers of obesity and progression from Barrett's esophagus to esophageal adenocarcinoma. Clin Gastroenterol Hepatol. 2013;11(8):934-43.

11. Thrift AP, Hilal J, El-Serag HB. Metabolic syndrome and the risk of Barrett's oesophagus in white males. Aliment Pharmacol Ther. 2015:41(11):1182-9.

12. Di Caro S, Cheung WH, Fini L, Keane MG, Theis B, Haidry R, Di Renzo L, De Lorenzo A, Lovat L, Batterham RL, et al. Role of body composition and metabolic profile in Barrett's oesophagus and progression to cancer. Eur J Gastroenterol Hepatol. 2016;28(3):251-60.

13. Lundell LR, Dent J, Bennett JR, Blum AL, Armstrong D, Galmiche JP, Johnson F, Hongo M, Richter JE, Spechler SJ, et al. Endoscopic assessment of oesophagitis: clinical and functional correlates and further validation of the Los Angeles classification. Gut. 1999;45(2):172-80

14. WHO Expert Consultation. Appropriate body-mass index for Asian populations and its implications for policy and intervention strategies. Lancet. 2004;363(9403):157-63.

15. Alberti KG, Eckel RH, Grundy SM, Zimmet PZ, Cleeman Jl, Donato KA, Fruchart JC, James WP, Loria CM, Smith SC Jr. Harmonizing the metabolic syndrome: a joint interim statement of the international diabetes federation task force on epidemiology and prevention; National Heart, Lung, and Blood Institute; American Heart Association; world heart federation; international atherosclerosis society; and International Association for the Study of obesity. Circulation. 2009;120(16):1640-5.

16. Turner RC, Holman RR, Matthews D, Hockaday TD, Peto J. Insulin deficiency and insulin resistance interaction in diabetes: estimation of their relative contribution by feedback analysis from basal plasma insulin and glucose concentrations. Metabolism. 1979:28(11):1086-96.

17. Kim JW, Kim DH, Roh YK, Ju SY, Nam HY, Nam GE, Kim DW, Lee SH, Lee CW, Han K, et al. Serum ferritin levels are positively associated with metabolically obese normal weight: a Nationwide population-based study. Medicine (Baltimore). 2015;94(52):e2335.

18. Ko SH, Baeg MK, Ko SY, Jung HS, Kim P, Choi MG. Obesity and metabolic unhealthiness have different effects on colorectal neoplasms. J Clin Endocrinol Metab. 2017:102(8):2762-9.

19. Andersson T, Alfredsson L, Kallberg H, Zdravkovic S, Ahlbom A. Calculating measures of biological interaction. Eur J Epidemiol. 2005;20(7):575-9.

20. Knol MJ, VanderWeele TJ, Groenwold RH, Klungel OH, Rovers MM, Grobbee DE. Estimating measures of interaction on an additive scale for preventive exposures. Eur J Epidemiol. 2011;26(6):433-8.
21. El-Serag H. Role of obesity in GORD-related disorders. Gut. 2008:57(3):281-4.

22. Pointer SD, Rickstrew J, Slaughter JC, Vaezi MF, Silver HJ. Dietary carbohydrate intake, insulin resistance and gastro-oesophageal reflux disease: a pilot study in European- and African-American obese women. Aliment Pharmacol Ther. 2016;44(9):976-88.

23. Hsu CS, Wang PC, Chen JH, Su WC, Tseng TC, Chen HD, Hsiao TH, Wang CC, Lin HH, Shyu RY, et al. Increasing insulin resistance is associated with increased severity and prevalence of gastro-oesophageal reflux disease. Aliment Pharmacol Ther 2011:34(8):994-1004.

24. Tai CM, Lee YC, Tu HP, Huang CK, Wu MT, Chang CY, Lee CT, Wu MS, Lin JT, Wang WM. The relationship between visceral adiposity and the risk of erosive esophagitis in severely obese Chinese patients. Obesity (Silver Spring). 2010;18(11):2165-9.

25. Ruggiero C, Metter EJ, Cherubini A, Maggio M, Sen R, Najjar SS, Windham GB, Ble A, Senin U, Ferrucci L. White blood cell count and mortality in the Baltimore longitudinal study of aging. J Am Coll Cardiol. 2007;49(18):1841-50.

26. Wu YW, Tseng PH, Lee YC, Wang SY, Chiu HM, Tu CH, Wang HP, Lin JT, Wu MS, Yang WS. Association of esophageal inflammation, obesity and gastroesophageal reflux disease: from FDG PET/CT perspective. PLoS One. 2014;9(3):e92001.

27. Rieder F, Biancani P, Harnett K, Yerian L, Falk GW. Inflammatory mediators in gastroesophageal reflux disease: impact on esophageal motility, fibrosis, and carcinogenesis. Am J Physiol Gastrointest Liver Physiol. 2010;298(5):G571-81.

28. Park JJ, Kim JW, Kim HJ, Chung MG, Park SM, Baik GH, Nah BK, Nam SY, Seo $\mathrm{KS}, \mathrm{Ko} \mathrm{BS}$, et al. The prevalence of and risk factors for Barrett's esophagus in a Korean population: a nationwide multicenter prospective study. J Clin Gastroenterol. 2009;43(10):907-14.

29. Lee IS, Choi SC, Shim KN, Jee SR, Huh KC, Lee JH, Lee KJ, Park HS, Lee YC, Jung $H Y$, et al. Prevalence of Barrett's esophagus remains low in the Korean population: nationwide cross-sectional prospective multicenter study. Dig Dis Sci. 2010:55(7):1932-9.

\section{Ready to submit your research? Choose BMC and benefit from:}

- fast, convenient online submission

- thorough peer review by experienced researchers in your field

- rapid publication on acceptance

- support for research data, including large and complex data types

- gold Open Access which fosters wider collaboration and increased citations

- maximum visibility for your research: over $100 \mathrm{M}$ website views per year

At BMC, research is always in progress.

Learn more biomedcentral.com/submissions 